\title{
CHARCOT OSTEOARTHROPATHY: ONE DISEASE, TWO PRESENTATIONS
}

\author{
Nina L. Petrova ${ }^{1,2}$ and Michael E. Edmonds ${ }^{1}$ \\ ${ }^{1}$ Diabetic Foot Clinic, King's College Hospital, London, UK, and ${ }^{2}$ Clinic of Endocrinology \\ and Metabolic Diseases, Medical University, Varna, Bulgaria
}

Charcot osteoarthropathy or Charcot foot is a disabling complication of diabetes and is associated with poor prognosis and high mortality. Its pathogenesis is not fully understood and its treatment is at best symptomatic. Furthermore, it is not known whether there is a specific type of neuropathy which affects osteoclastic activity, and thereby leads to reduction of bone mineral density and the development of Charcot osteoarthropathy. Recently it has been proposed that there is a difference in the presentation of Charcot osteoarthropathy between type 1 and type 2 diabetes. This article reviews the link between underlying osteopenia, abnormal biomechanical forces and type of neuropathy, and their varying interaction in the pathogenesis of Charcot osteoarthropathy in type 1 and type 2 diabetes. Further attention is drawn to the newly discovered osteoprotegerin/receptor activator of nuclear factor kappaB ligand (OPG/RANKL) cytokine system, which controls bone resorption. Increased osteoclastic activity in the acute Charcot foot may be associated with altered expression of OPG/RANKL signaling pathway and modulation of the OPG/RANKL equilibrium in Charcot osteoarthropathy may provide additional therapeutical option to manage this difficult condition. Biomed Rev 2005; 16: 43-48.

Key words: Charcot osteoarthropathy, diabetes, fracture, neuropathy, OPG/RANKL, osteopenia

\section{INTRODUCTION}

Charcot osteoarthropathy or Charcot foot is a major complication of diabetes and its pathogenesis remains poorly understood (1). It often presents without warning and can rapidly deteriorate into severe and irreversible foot deformity leading then to ulceration and amputation. Prognosis of this condition is poor and mortality is high $(2,3)$. There is considerable controversy regarding its pathogenesis and the treatment is at best symptomatic. Natural history studies have indicated that the important initial lesions are fractures which are spontaneous in most cases. Due to underlying peripheral neuropathy, the fractures are not painful and the patient who is unaware of the condition is able to tolerate walking. Eventually a stage with multiple fractures and loss of normal foot architecture develops, that is, the Charcot foot (4).

Fractures are often juxta-articular and can cause the joint to become unstable and subject to abnormal stresses which will result in erosion of bone and cartilage. Fractures of significant magnitude were responsible for initiating joint changes in the majority of the 118 cases of Charcot foot reported by Johnson (4). In this classical review, he was convinced that fractures are the harbinger of the Charcot foot (5). However, the reason for

Received 6 September 2005 and accepted 15 October 2005.

Correspondence and reprint requests to Dr Nina Petrova, Diabetic Foot Clinic, King's College Hospital, Denmark Hill, London SE5 9RS, UK. Tel.: 442073463 223, Fax: 442073464 536, E-mail: petrovanl@yahoo.com 
these fractures is not fully understood. It is possible that there is increased fragility of bone associated with a reduction of bone density in the foot that would increase susceptibility to fracture. Alternatively, these may be stress fractures, occurring in bones with normal bone density but subjected to abnormal biomechanical forces. Furthermore, it is not known whether there is a specific type of neuropathy which by affecting osteoclastic activity, leads to reduction of bone mineral density and the development of Charcot osteoarthropathy.

\section{IS THERE UNDERLYING OSTEOPENIA THAT PREDISPOSES TO FRACTURES AND THEN TO THE DEVELOPMENT OF THE CHARCOT FOOT?}

Previous studies have suggested that reduced bone mineral density in diabetic patients predisposes to fracture, leading to Charcot osteoarthropathy. A reduced bone mineral density in the lower limbs of Charcot patients compared with nonCharcot neuropathic patients has been reported (6) as well as reduced stiffness in the calcaneum in the Charcot and non-Charcot foot compared with controls (7). However, these studies did not differentiate between type 1 and type 2 diabetes and we demonstrated that at the onset of Charcot osteoarthropathy, there is a pre-existing osteopenia only in type 1 but not in type 2 diabetes as indicated by a reduced bone mineral density in the non-Charcot foot compared with controls (8) and a recent study has shown a link between type 1 diabetes, osteopenia and fractures (9).

Thus the association between diabetes and osteopenia is more marked in type 1 rather than type 2 diabetes and interestingly a relatively high preponderance of patients with longstanding type 1 diabetes developing Charcot osteoarthropathy at a young age has been reported (10). This overrepresentation of type 1 diabetes suggests that there may be additional predisposing factors to Charcot osteoarthropathy in type 1 diabetes and underlying osteopenia may be one of them.

\section{IS THERE A BIOMECHANICAL ABNORMALITY THAT MAY LEAD TO FRACTURES IN BONES WITH NORMAL BONE MINERAL DENSITY AND THUS LEAD TO THE DEVELOPMENT OF THE CHARCOT FOOT?}

It is possible that fractures in type 2 diabetes are result of abnormal biomechanical forces on the background of global neurological deficit. Indeed, stress fractures of the bone were the most frequent cause of Charcot osteoarthropathy in one series of patients (5). Fractures may result from alteration of weight bearing and load in the foot. Armstrong reported elevated peak plantar pressures in the Charcot foot and interestingly also in the non-Charcot foot in type 2 diabetic patients (11) and patients with Charcot osteoarthropathy who presented with dislocation pattern of osteoarthropathy had a higher bone mineral density compared with patients who presented with fractures (9). Weight-bearing on a neuropathic foot with weak ankle dorsiflexors causes the triceps surae to forcefully plantarflex the foot resulting in increased pressure over the metatarsal-phalangeal joints, a slapping gait and stress at the tarsometatarsal, naviculo-cuneiform and midtarsal joints once calf contracture occurs (1). Achilles tendon shortening may predispose to Charcot foot collapse (12) by pulling the hind foot into plantar flexion which results in markedly increased load in the forefoot (13). Thus high peak pressure and sensory neuropathy in the forefoot coupled with a relative equinus deformity may predispose to Charcot osteoarthropathy (11) as a consequence of an increased pressure in the mid-foot. Recent studies have shown that the equinus foot alters the normal profile of footfall, moving initial contact away from the lateral aspect of the heel to the forefoot area, in essence missing the load response phase of gait (the first rocker). This will result in forces of approximately 1.5-2 times body weight being transmitted to a region with limited extrinsic shock absorption properties. Furthermore, due to the foot's normal pronation profile, a forefoot impact may result in excessive stress at the articulations of the medial cuneiform, resulting in micro- and eventual macrotrauma (14). This may explain why the tarsometatarsal joint (Lisfranc joint) is the commonest site of involvement of Charcot osteoarthropathy (1) and increased pressure in the forefoot may result in fracture/dislocation of the tarsometatarsal joint and eventual collapse of the medial longitudinal arch. Thus abnormal foot biomechanics in the insensate neuropathic limb may lead to repetitive trauma and result in fractures and development of Charcot foot.

Although both osteopenia and abnormal biomechanical forces in the background of neuropathy may have varying interaction in the pathogenesis of Charcot osteoarthropathy in type 1 and type 2 diabetes, the final common precipitating event is usually trauma, which determines the site of involvement on the background of peripheral neuropathy, which has been demonstrated in both type 1 and type 2 patients with Charcot osteoarthropathy.

\section{IS THERE A SPECIFIC TYPE OF NEUROPATHY THAT MAY LINK OSTEOPENIA AND DIABETES?}

Several investigations have shown that neuropathy may aggravate the deficit of bone mass in type 1 diabetes. A decreased bone mineral density in the femoral neck and distal limb in association with peripheral neuropathy has been 
reported (15) and using quantitative ultrasound, significantly reduced bone mineral density in the calcaneum in patients with severe neuropathy has been demonstrated (16). However, the type of neuropathy leading to osteopenia has not yet been investigated. Furthermore, once Charcot osteoarthropathy has developed there is a reduction of bone mineral density in the Charcot foot compared with the non-Charcot foot in both type 1 and type 2 diabetes. The reasons for this underlying osteopenia predisposing to the development of Charcot osteoarthropathy in type 1 diabetes and the subsequent reduction in bone mineral density in both type 1 and type 2 diabetes, once Charcot osteoarthropathy has developed, are unknown but this may be related to a specific type of neuropathy.

Clinical observations have indicated that local innervation plays a modulating role in bone growth, repair and remodeling. Patients with neurological disorders such as spinal cord injury and arthritis exhibit localised osteopenia, bone fragility, excessive callus formation and altered fracture healing. Identification of the nerve-derived signalling molecules, using immunochistochemistry has enabled the identification of these nerve fibres of osseous tissues. Calcitonin generelated peptide (CGRP) and substance P (SP) have been of much interest because these neuropeptides are found in unmyelinated (C type) and small myelinated (A- -5 type) primary sensory neurons, namely nociceptive fibres $(17,18)$. The terminal structure of the osseous CGRP-containing nerves reaches directly osteoblasts, osteoclasts, and periosteal lining cells, and are a source of local CGRP which act as a local modulator of bone metabolism. CGRP increases osteoblastic cyclic adenosine monophosphate via acting on their specific CGRP receptors $(19,20)$ and thus stimulating osteogenesis (21). Osseous CGRP-containing fibres are also involved in pathologic events of bone. The density of CGRP fibres is increased near the sites of postfracture osteogenesis (healing callus) (22) and is decreased at the stumps of non-union (23). Damage to the CGRP-releasing terminals may result in loss of the trophic and modulatory factors provided by the peptide transmitters $(19-21,24,25)$. CGRP positive nerve fibres are crucial element of bone metabolism during growth and development and their impairment at a young age may lead to impaired bone formation (26).

Thus small fibre neuropathy may play two possible roles in the pathogenesis of Charcot osteoarthropathy. Firstly, CGRP deficiency, as a result of small fibre neuropathy presenting at young age in patients with type 1 diabetes, may lead to impaired osteogenesis and impede achievement of peak bone mass at adolescence and indeed reduced bone mineral density has been reported in post-teen age years in patients with type
1 diabetes (27). Secondly, the loss of CGRP containing nerve fibres and their modulatory effect on bone, may lead to impaired healing of microfractures resulting from a minor trauma in the insensate foot in both type 1 and type 2 diabetes, thus triggering the development of Charcot osteoarthropathy.

A distinct syndrome has been described in young insulin dependent diabetic subjects in their twenties and thirties, often women, who develop small fibre neuropathy in association with Charcot osteoarthropathy $(28,29)$. This is often associated with symptomatic autonomic neuropathy. Despite their youth these patients demonstrate medial calcification of the arteries of the feet, yet do not experience numbness of their feet, retaining normal light touch and near-normal vibration perception. The clinical manifestations are almost solely due to small nerve fibre damage. This striking syndrome is not rare, is highly destructive, and is clearly different from the commoner problem of numb, ulcerated feet. We have previously described an association of neuropathy with vascular calcification but the mechanism is not fully understood (30).

Thus in type 1 diabetes, there appears to be a syndrome of small fibre neuropathy, vascular calcification and peripheral osteopenia which then results in pathological fractures and Charcot osteoarthropathy whilst in type 2 diabetes peripheral neuropathy and autonomic neuropathy associated with vascular calcification may be present at the time of diagnosis of type 2 diabetes and thus subsequently increase the risk of Charcot osteoarthropathy.

\section{WHAT THEN COULD EXPLAIN THE LINK BETWEEN SMALL FIBRE NEUROPATHY, CALCIFICATION, OSTEOPENIA AND CHARCOT OSTEOARTHROPATHY?}

A recently described cytokine system, which controls bone resorption may provide this link. This is the osteoprotegerin(OPG)/ receptor activator of nuclear factor-kappaB ligand (RANKL) signaling pathway which may be disturbed in diabetic neuropathy (31). A small pilot study has demonstrated increased concentrations of OPG in patients with neuropathy compared with non-neuropathic patients and healthy controls (32).

The RANKL has been identified as an essential cytokine for the formation and activation of osteoclasts. RANKL activates its receptor, which is expressed on osteoclasts, thus promoting osteoclastogenesis. RANKL is expressed on bone forming osteoblasts and thus bone resorption and bone formation are coupled through RANKL. The effects of RANKL are physiologically counterbalanced by OPG, which acts as a decoy receptor (a soluble receptor that acts as an antagonist) for RANKL. The balance between RANKL and OPG determines osteoclast functions. Expression of RANKL 
and OPG is coordinated to regulate bone resorption and density and negatively by controlling activation state of RANK on osteoclasts. Alterations of the OPG/RANKL ratio are critical in the pathogenesis of bone diseases that result from increased bone resorption (33). Transgenic mice overexpressing OPG develop osteopetrosis and, conversely, OPG knockout mice develop severe osteoporosis (34). These mice also develop arterial calcification which may also be influenced by the OPG/ RANKL cytokine system (35). It is well known that there is a high clinical prevalence and coincidence of arterial calcification and cardiovascular disease in patients with osteoporosis thus supporting the hypothesis that the OPG/RANKL system may influence both osteoporosis and calcification. (36-38). Furthermore, there is a significant correlation of serum OPG levels with diabetes and with cardiovascular mortality and this raises the possibility that OPG may be a cause of or a marker for arterial calcification (39).

Recent studies on the OPG/RANKL signaling pathway provide a deeper understanding of how diverse physiological and pathophysiological signals exert their effect on this cytokine pathway to induce osteoclastogenesis, bone resorption and skeletal remodeling, and so control bone mass. Mutations in the genes encoding RANK and OPG cause bone diseases and therefore inhibition of the RANKL signaling pathway may be a viable therapeutic strategy for treatment of diseases with excessive resorption (40). In a recent study in Charcot osteoarthropathy we demonstrated raised levels of OPG in type 1 and type 2 patients with Charcot osteoarthropathy compared with type 1 and type 2 diabetic control patients (41). It is possible that the increased OPG levels reflect a protective mechanism to inhibit osteoclast formation and thus compensate for increased osteoclastic activity resulting from an increased activity of RANKL in acute Charcot osteoarthropathy. The RANK/RANKL signaling pathway has been shown to be essential for osteoclast differentiation in inflammatory arthritis. Furthermore, imbalance between RANKL and OPG has recently been shown to lead to osteoarticular pathology in inflammatory arthritis and in severe osteolysis (42). Expression of OPG/RANKL is known to be modulated by various factors including tumour necrosis factor-alpha, interleukins, calcitonin, and CGRP. The latter inhibits osteoclast function and stimulates bone formation. CGRP is a neuropeptide that acts as a neurotransmitter in small fibres (C-fibres) $(43,44)$. CGRP is deficient in small fibre neuropathy and this may result in osteopenia via the OPG/RANKL cytokine pathway. Small fibre neuropathy may enhance the ratio of RANKL to OPG and thus promote osteoclastogenesis and accelerate bone resorption. Furthermore in Charcot osteoarthropathy, there is early fracture which itself stimulates increased expression of RANKL. In the presence of neuropathy, with deficiency of
CGRP, this may lead to overexpression of RANKL and an increased OPG/RANKL ratio may result in excessive osteoclastic activity leading to Charcot osteoarthropathy.

Thus altered expression of OPG/RANKL secondary to small fibre neuropathy may have two roles: (i) by promoting osteopenia in type 1 diabetes to increase susceptibility to Charcot osteoarthropathy, and (ii) by stimulating osteoclastogenesis in the actual development of Charcot osteoarthropathy in both type 1 and type 2 diabetes.

\section{CONCLUSION}

Thus the observed difference in bone mineral density in the background of sensory deficit may lead to different pathways in the development of Charcot osteoarthropathy in type 1 and type 2 diabetes, as determined by the neurovascular and neurotraumatic theories of its pathogenesis $(1,45)$. In type 1 diabetes, the underlying osteopenia secondary to increased blood flow and autonomic neuropathy may lead to pathological fractures and Charcot neuropathic osteoarthropathy as described in the neurovascular theory (46). In contrast, in type 2 diabetes, where bone mineral density is normal, repetitive trauma in the insensitive foot with elevated plantar pressure $(11,47)$ as a result of the increased body mass index and abnormal biomechanical forces may lead to stress fractures and Charcot osteoarthropathy in accordance with the neurotraumatic theory. Increased osteoclastic activity in the acute Charcot foot may be associated with altered expression of OPG/RANKL signaling pathway and modulation of the OPG/RANKL equilibrium in Charcot osteoarthropathy may provide additional therapeutical target to manage this difficult condition.

\section{ACKNOWLEDGEMENTS}

Nina L. Petrova was supported by Diabetes UK Grant: BDA: RD 01/002284 and grant BDA:05/0003025.

\section{REFERENCES}

1. Sanders LJ, Frykberg RG. Charcot neuroarthropathy of the foot. In: Levin ME, O’Neal LW, Bowker JH, Pfeifer MA, editors. The Diabetic Foot, 6th edn, St Louis, Mosby, 2001: 21: 439-465.

2. Sinacore DR, Withrington NC. Recognition and management of acute (Charcot) arthropathies of the foot and ankle. J Orthop Sports Phys Ther 1999; 29: 733-746.

3. Gazis A, Pound N, Macfarlane R, Treece K, Game F, Jeffcoate W. Mortality in patients with diabetic neuropathic osteoarthropathy (Charcot foot). Diabet Med 2004; 21: 1243-1246. 
4. Johnson JTH. Neuropathic fractures and joint injures. Pathogenesis and rationale of prevention and treatment. J Bone Joint Surg 1967; 49A: 1-30.

5. Larsen K, Holstein PE. Stress fractures as the cause of Charcot feet. In: Bakker K, Nieuwebhuijzen Kruseman AC, editors. The Diabetic Foot. Proceedings of the First International Symposium on the Diabetic Foot. Excerpta Medica, 1991; 108-116.

6. Young MJ. Marshall A. Adams JE. Selby PL. Boulton AJ. Osteopenia, neurological dysfunction, and the development of Charcot neuroarthropathy. Diabet Care 1995; 18: 34-38.

7. Jirkovska A. Kasalicky P, Boucek P, Hosova J, Skibova J. Calcaneal ultrasonometry in patients with Charcot osteoarthropathy and its relation with densitometry in the lumbar spine and femoral neck and with markers of bone turnover. Diabet Med 2001; 18: 495-500.

8. Petrova NL, Foster AVM, Edmonds ME. Calcaneal bone mineral density in patients with Charcot neuropathic osteoarthropathy: differences between type 1 and type 2 diabetes. Diabet Med 2005; 22: 756-761.

9. Herbst SA, Jones KB, Saltzman CL. Pattern of diabetic neuropathic arthropathy associated with the peripheral bone mineral density. J Bone Joint Surg Br 2004; 86: 378-383

10. Petrova NL, Foster AVM, Edmonds ME. Difference in presentation of Charcot osteoarthropathy in type 1 compared with type 2 diabetes. Diabet Care 2004; 27: 1235-1236.

11. Armstrong DG, Lavery LA. Elevated peak planter pressures in patients who have Charcot arthropathy. $J$ Bone Joint Surg Am 1998; 80: 365-369.

12. Grant WP, Sullivan R, Sonenshine DE, Adam M, Slusser $\mathrm{JH}$, Carson KA, et al. Electron microscopic investigation of the effects of diabetes mellitus on the Achilles tendon. J Foot Ankle Surg 1997; 36: 272-278.

13. Orendurff MS, Aiona MD, Dorociak RD, Pierce RA. Length and force of the gastrocnemius and soleus during gait following tendo Achilles lengthenings in children with equines. Gait Posture 2002; 15: 130-135.

14. Willems T, Witvrouw E, Delbaere K, De Cock A, De Clercq D. Relationship between gait biomechanics and inversion sprains: a prospective study of risk factors. Gait Posture, 2005; 21: 379-87.

15. Forst T, Pfutzner A, Kann P, Schehler B, Lobmann R, Schafer $\mathrm{H}$, et al. Peripheral osteopenia in adult patients with insulin-dependent diabetes mellitus. Diabet Med 1995; 12: 874-879.
16. Rix M, Andreassen H, Eskildsen P. Impact of peripheral neuropathy on bone density in patients with type 1 diabetes. Diabet Care 1999; 22: 827-831.

17. Hökfelt T, Kellerth JO, Nilsson G, Pernow B. Morphological report for transmitter role of substance $\mathrm{P}$, immunohistochemical localization in the central nervous system and in primary sensory neurones. Science 1975; 190: 889-890.

18. Lee Y, Takami K, Kawai Y, Girgis S, Hillyard CJ, MacIntyre I, et al. Distribution of calcitonin gene-related peptide in the rat peripheral nervous system with reference to its coexistence with substance P. Neuroscience 1985; 15: 1227-1237.

19. Crawford A, Evans DB, Skjodt H, Beresford JN, Maclntyre I, Russell RGG. Effects of human calcitonin gene-related peptide on human bone-derived cells in culture. Bone 1986; 7: 157-158.

20. Bjurholm A, Kreicbergs A, Schultzberg M, Lerner UH. Neuroendocrine regulation of cyclic AMP formation in osteoblastic cell lines and primary bone cells. $J$ Bone Miner Res 1992; 7: 1011-1019.

21. Bernard GW, Shih. The osteogenic stimulating effect of neuroactive calcitonin gene-related peptide. Peptides 1990; 11: 625-632.

22. Hukkanen M, Konttinen YT, Santavirta S, Paavolainen $\mathrm{P}, \mathrm{Gu} \mathrm{XH}$, Terenghi G, et al. Rapid proliferation of calcitonin gene-related peptide-immunoreactive nerves during healing of rat tibial fracture suggests neural involvement in bone growth and remodeling. Neuroscience 1993; 54: 969-979.

23. Santavirta S, Konttinen YT, Nordstrom D, Makela A, Sorsa T, Hukkanen M, et al. Immunologic studies of nonunited fractures. Acta Orthop Scand 1992; 63: 579586.

24. Beuerman RW. Sensory denervation of the rabbit cornea affects epithelial properties. Exp Neurol 1980; 69:196201.

25. Nilssen J, von Euler AM, Dalgaard CJ. Stimulation of connective tissue cell growth by substance $P$ and substance K. Nature 1985; 315: 61-63.

26. Hara-Irie F, Amizuka N, Ozawa H. Immunohistochemical and ultrastructural localization of CGRP-positive nerve fibers at the epiphyseal trabecules facing the growth plate of rat femurs. Bone 1996; 18: 29-39.

27. Liu EY, Wactawski-Wende J, Donahue RP, Dmochowski J, Hovey KM, Quattrin T. Does low bone mineral density start in post-teenage years in women with type 1 diabetes? Diabet Care 2003; 26: 2365-2369.

28. Winkler AS, Ejskjaer N, Edmonds M, Watkins PJ. Dis- 
sociated sensory loss in diabetic autonomic neuropathy. Diabet Med 2000; 17: 457-462.

29. Edmonds ME. Autonomic neuropathy In: De Forenxo RA, Ferrannini E, Keen H, Zimmet P, editors. International Textbook of Diabetes, $3^{\text {rd }}$ edn, John Wiley \&Sons, Ltd, Chichester, West Sussex, England 2004; 70 (vol. 2): 1263-1282.

30. Edmonds ME, Morrison N, Laws JW, Watkins PJ. Medial arterial calcification and diabetic neuropathy. $\mathrm{Br} \mathrm{Med} J$ (Clin Res Ed) 1982; 284: 928-930.

31. Jeffcoate W. Vascular calcification and osteolysis in diabetic neuropathy - is RANK-L the missing link? Diabetologia 2004; 47: 1488-1492.

32. Jeffcoate WJ, Monaghan J, Game FL. Neuropathy, osteoporosis and arterial calcification - do RANK-L and osteoprotegerin provide the missing link? Diabetologia 2004; 47 (Suppl 1): A375, No 1047 [Abstract].

33. Hofbauer LC, Schoppet M. Clinical implications of the osteoprotegerin/RANKL/RANK system for bone and vascular diseases. JAMA 2004; 292: 490-495.

34. Simonet WS, Lacey DL, Dunstan CR, Kelly M, Chang MS, Luthy R, et al. Osteoprotegerin: a novel secreted protein involved in the regulation of bone density. Cell 1997; 89: 309-319.

35. Bucay N, Sarosi I, Dunstan CR, Morony S, Tarley J, Capparelli $\mathrm{C}$, et al. Osteoprotegerin-deficient mice develop early onset osteoporosis and arterial calcification. Genes Dev 1998; 12:1260-1268.

36. Hak AE, Pols HA, van Hemert AM, Hofman A, Witteman JC. Progression of aortic calcification is associated with metacarpal bone loss during menopause: a populationbased longitudinal study. Arterioscler Thromb Vasc Biol 2000; 20:1926-1931.

37. Kado DM, Browner WS, Blackwell T, Gore R, Cummings SR. Rate of bone loss is associated with mortality in older women: a prospective study. J Bone Miner Res 2000; 15 : 1974-1980.

38. Boukhris R, Becker KL. Calcification of the aorta and osteoporosis. A roentgenographic study. JAMA 1972; 219:1307-1311.

39. Browner WS, Lui LY, Cummings SR. Associations of serum osteoprotegerin levels with diabetes, stroke, bone density, fractures, and mortality in elderly women. J Clin Endocrinol Metab 2001; 86: 631-637.

40. Boyle WJ, Simonet WS, Lacey DL. Osteoclast differentiation and activation. Nature 2003; 423: 337-342.

41. Korzon-Burakowska A, Saldana Chaparro RM, Petrova NL, Moniz C, Edmonds ME. Increased serum osteoprotegerin in type 1 but not in type 2 patients with Charcot osteoarthropathy. Diabet Med 2005; 22 (Suppl 2): 93, No P269 [Abstract].

42. Theoleyre S, Wittrant Y, Tat SK, Fortun Y, Redini F, Heymann D. The molecular triad OPG/RANK/RANKL: involvement in the orchestration of pathophysiological bone remodeling. Cytokine Growth Factor Rev 2004; 15 : 457-475.

43. Pittenger G, Vinik A. Nerve growth factor and diabetic neuropathy. Exp Diabesity Res 2003; 4: 271-285.

44. Gardiner NJ, Cafferty WB, Slack SE, Thompson SW. Expression of gp130 and leukaemia inhibitory factor receptor subunits in adult rat sensory neurones: regulation by nerve injury. J Neurochem 2002; 83: 100-109.

45. Rajbhandari SM, Jenkins RC, Davies C, Tesfaye S. Charcot neuroarthropathy in diabetes mellitus. Diabetologia 2002; 45: 1085-1096.

46. Edmonds ME. Roberts VC. Watkins PJ. Blood flow in the diabetic neuropathic foot. Diabetologia 1982; 22: 9-15.

47. Drerup B, Beckmann C. Wetz HH. Effect of body weight on plantar pressure in diabetic patients. Orthopade 2003; 32: 199-206 